\title{
An unusual electrocardiographic abnormality
}

\section{S Harris, M O’Neill, N Oliver, S Dubrey}

Answers on $p 545$.

A 70 year old man with chronic obstructive pulmonary disease and hypertension was admitted to hospital with a two month history of ankle swelling. On examination, the patient was in atrial fibrillation with an apical ventricular rate of 136 beats/min. worsening dyspnoea on exertion and The jugular venous pressure was not vis-

ible, but there was bilateral pitting

oedema to the knees. Auscultation of the chest revealed polyphonic wheeze and poor air entry but no crepitations.

An electrocardiogram (ECG) confirmed atrial fibrillation.

Full blood count, urea and creatinine, liver and thyroid function tests, and bone profile were all within normal limits. The plasma magnesium was $0.56 \mathrm{mmol} / \mathrm{l}$.

The patient was treated with oral digoxin, intravenous frusemide, and nebulised salbutamol.

Within 24 hours of admission, the patient had a cardiac arrest and was successfully resuscitated. Three further cardiac arrests involving a similar rhythm disturbance occurred during the second day.

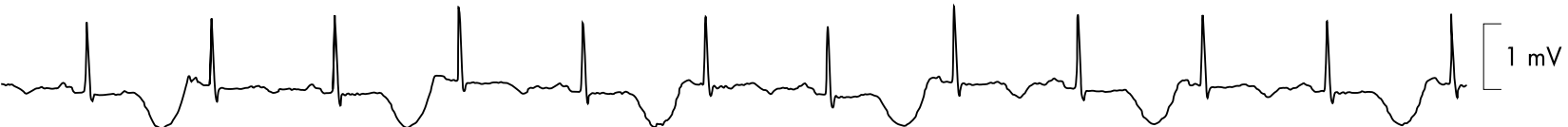

Figure 1 Lead II of the surface ECG.

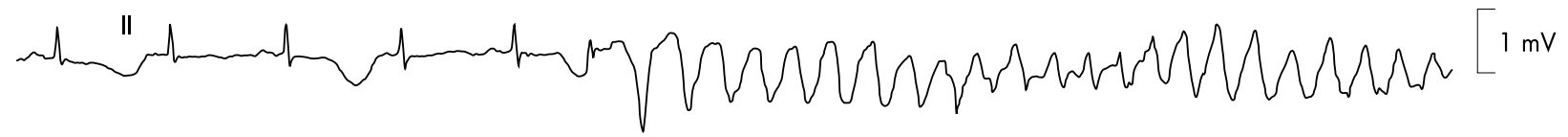

H

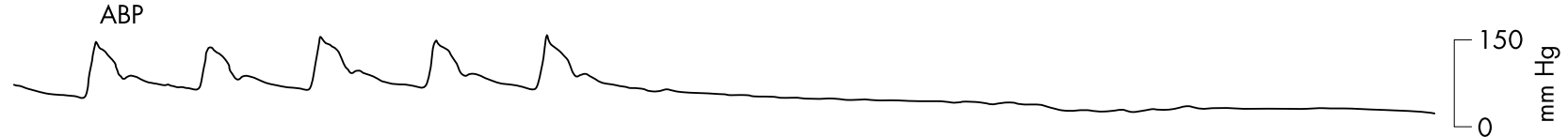

Figure 2 Data from a representative cardiac arrest. Traces from the top down are lead II and lead V of the surface ECG. The lowermost trace shows arterial blood pressure (ABP).
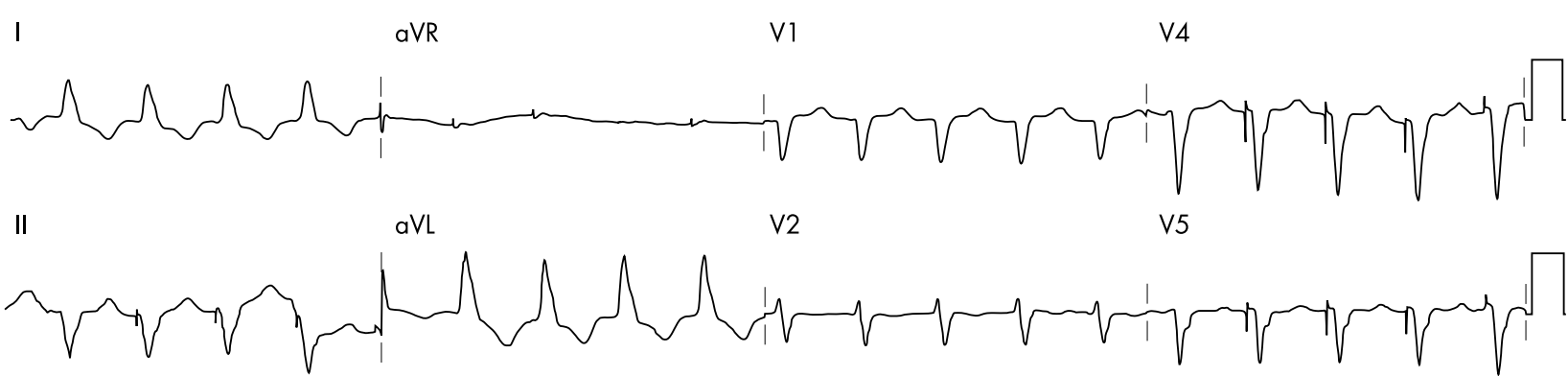

III

$\mathrm{aVF}$

V3

V6

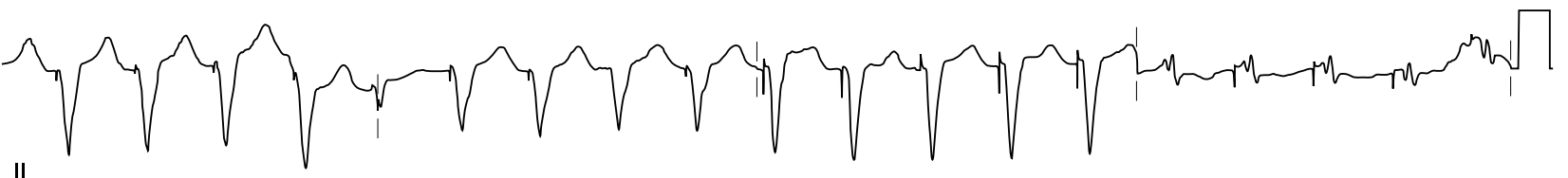

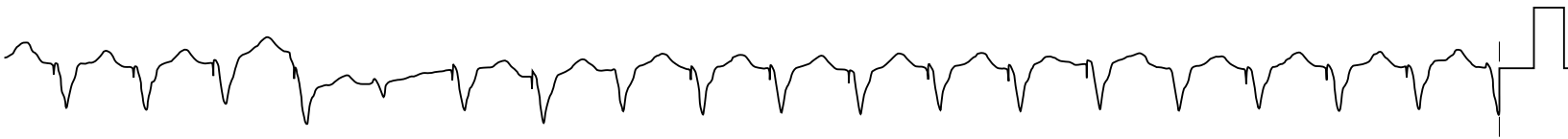

Figure 3 Twelve lead surface ECG. 


\section{QUESTIONS}

(1) What is shown in fig 1 , and what is its significance?

(2) What is the arrhythmia in fig 2?

(3) What was the procedure used to treat the patient in fig 3?

Postgrad Med J 2003;79:539

\section{Authors' affiliations}

S Harris, M O'Neill, N Oliver, S Dubrey, Department of Cardiology, Hillingdon Hospital, Uxbridge, Middlesex, UK

Correspondence to: Dr Harris; steve.harris@doctors.org.uk
Submitted 10 September 2002

Accepted 3 December 2002

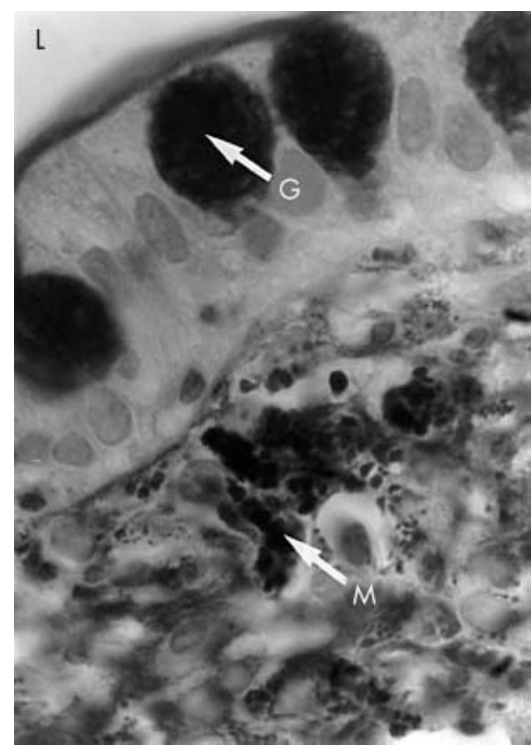

Figure 1 Jejunal biopsy specimen stained with PAS $\times 400$. Positive staining seen within macrophages in the lamnia propria $(G$, goblet cell within the mucosa; $L$, lumen; $M$, macrophage containing PAS positive granules).

(2) What is the pathognomonic central nervous system manifestation (dementia; cerebellar syndrome; supranuclear ophthalmoplegia; facial and ocular myoclonus; brainstem syndromes)?

(3) What is the diagnostic test?

(4) How does one treat this condition?

Postgrad Med J 2003;79:540

\section{Authors' affiliations}

R C Rakshit, J D Mackay, Blackpool Victoria Hospital, Whinney Heys Road, Blackpool FY3 8NR, UK

Correspondence to: Dr Rakshit rinti1@hotmail.com

Submitted 14 August 2002

Accepted 5 March 2003
Infection

\section{A diagnostic conundrum}

\section{R C Rakshit, J D Mackay}

Answers on p 545.

$\Lambda^{37}$ 37 year old man with learning difficulties presented to our hospital in 1999 with anorexia, $12 \mathrm{~kg}$ weight loss, swelling of the legs, and night sweats. On examination he had a dusky generalised pigmentation but no rash and slight hepatomegaly. He had a microcytic anaemia (haemoglobin 11.9 $\mathrm{g} / \mathrm{l}$, mean corpuscular volume $75 \mathrm{fl}$ ) and erythrocyte sedimentation rate $89 \mathrm{~mm} /$ hour. Blood biochemistry profile, serial urine samples for microscopy and culture, and chest radiography were normal. Abdominal ultrasound revealed a gross right sided hydronephrosis, but was thought to be a long standing problem caused by pelviureteric junction obstruction. There was no evidence of a pyonephrosis.

A bone marrow examination revealed non-specific reactive changes only. Lymphocyte markers were normal. Computed tomography of the chest and abdomen showed multiple enlarged lymph nodes in the mediastinum, paraaortic area, mesentery, inguinal regions, and axilla. Lymphoma was ruled out with two lymph node biopsies, the first one of which revealed non-caseating granulomata and the second showed extensive fibrosis. Toxoplasma and bartonella serology were negative. A liver biopsy was performed and the specimen was too fragmented for histology but smears and cultures for acid-fast bacilli were negative. The patient remained unwell during these investigations and was hypoalbuminaemic $(28 \mathrm{~g} / \mathrm{l})$. All these above mentioned investigations took a long time because they were difficult to organise with his learning difficulties. We had to get most of them done under a general anaesthetic. This was between 1999 and the next admission in 2001

He was admitted to the hospital in February 2001 with a two week history of intractable diarrhoea with yellow plasticine-like stools, faecal and urinary incontinence, anorexia, vomiting, and 4 $\mathrm{kg}$ weight loss over three months. He had abdominal distension due to a bowel ileus, confirmed on abdominal radiography. There was no evidence of any neurological involvement. His haemoglobin was $6.6 \mathrm{~g} / \mathrm{l}$, mean corpuscular volume $74 \mathrm{fl}$, C-reactive protein $108 \mathrm{mg} / \mathrm{l}$, and albumin $15 \mathrm{~g} / \mathrm{l}$. Antiendomysial antibodies were negative. A barium follow-through examination of his bowel showed thickened jejunal mucosal folds suggesting small bowel pathology. An enteroscopic jejunal biopsy showed oedematous villi with severe active chronic inflammatory cells including macrophages which had foamy granular eosinophilic cytoplasm. Staining of these granules showed that they were periodic acid Schiff (PAS)-diastase resistant (fig 1).

\section{QUESTIONS}

(1) What is the diagnosis in this case (tropical sprue; giardiasis; coeliac disease; Crohn's disease; Whipple's disease)? 


\section{QUESTIONS}

(1) What is the diagnosis?

\section{Progressive furrowing of skin with digital clubbing}

\section{A C Inamadar, A Palit, S B Athanikar, V V Sampagavi, N S Deshmukh, S I Korishetti}

Answers on p 546.

$\Lambda$ 27 year old man presented with gradual coarsening of his facial features noticed for the past two years. It was associated with marked oiliness of the facial skin and excessive sweating from the palms and soles. He had also noticed gradual painless swelling of the tips of his fingers and toes since puberty, which had assumed a bulbous appearance. He did not have any systemic or visual complaints or recent change in voice. There was no history of similar illness in any of his family members. Concern for his altered appearance brought him to hospital.

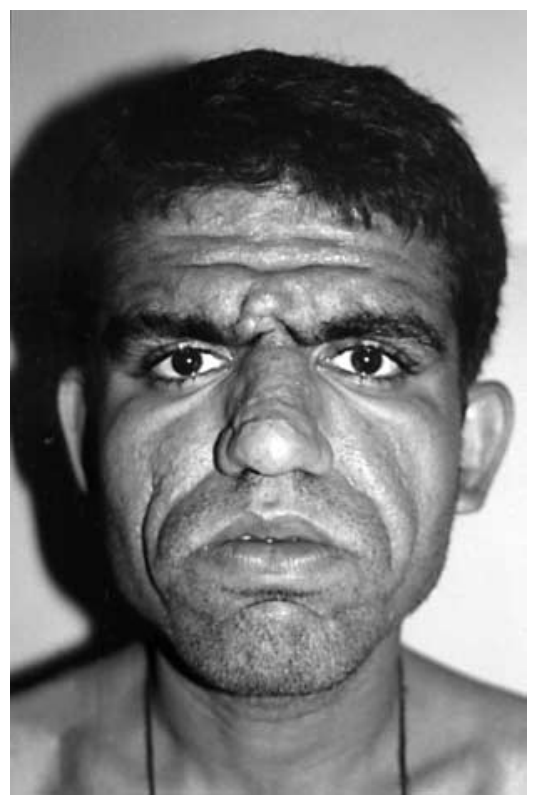

Figure 1 Deep furrowing of the face (published with patient's permission).
On examination, he was found to have a worried face, with deep horizontal furrowing on forehead, thick eyelids, broad nose, and prominent nasolabial folds (fig 1). The facial skin was thick and greasy. His scalp skin was doughy with deep, longitudinal, cerebriform folds along the vertex. Wrists and ankles were wider than usual with cylindrical contour. Hands and feet were broad with grade IV clubbing of the fingers (fig 2) and toes. The joints and digits were non-tender. Palms and soles were moist and velvety. His body proportions and vision were normal. A thorough systemic examination did not reveal any abnormality.

Routine haematological and biochemical investigations gave results within normal limits. Lateral skull radiography did not reveal any bony abnormality of the sella turcica. Serum growth hormone and prolactin levels were within normal limits. A skin biopsy specimen showed an increased number of fibroblasts, collagen bundles, and keratin cysts in the dermis. Radiographs of the wrist joint and hands are shown in figs 3 and 4 respectively.

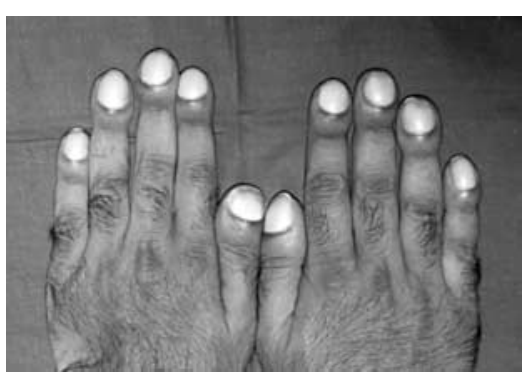

Figure 2 Clubbing of the fingers.
(2) What are the radiological findings shown?

(3) Which other conditions are to be differentiated clinically from this entity?

Postgrad Med J 2003;79:541

\section{Authors' affiliations}

A C Inamadar, A Palit, S B Athanikar, V V Sampagavi, N S Deshmukh, Department of Dermatology, BLDEA's SBMP Medical College, Hospital and Research Centre, Bijapur 586103, Karnataka, India

S I Korishetti, Department of Radiology

Correspondence to: Dr Inamadar;

Aparuna1@rediffmail.com

Submitted 24 March 2003

Accepted 28 May 2003

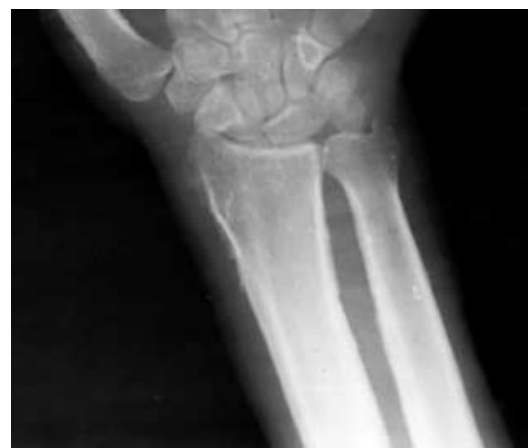

Figure 3 Radiograph of wrist joint.

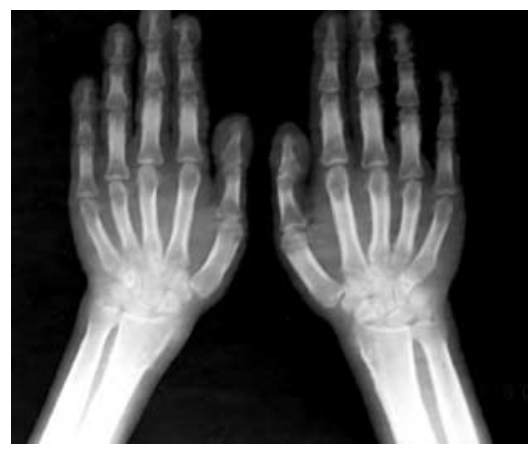

Figure 4 Radiograph of both hands. 


\section{Red eyes, reduced vision, and vomiting}

\section{N Dhingra, M T Watts}

Answers on p 546.

A 67 year old woman was referred by her general practitioner to our accident and emergency department with a two day history of nausea, vomiting, and blurred vision in both eyes. Her drug history included that of taking atenolol and paravastatin. Five

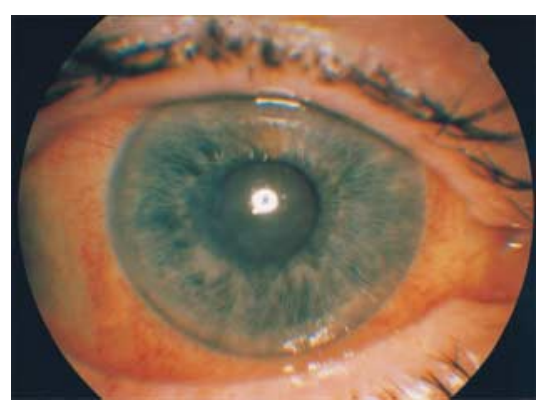

Figure 1 Right eye showing corneal oedema and iris atrophy. months before this referral, she had suffered a stroke and computed tomography then had revealed parietal lobe haemorrhage. She was examined by the casualty doctor and was subsequently admitted on the medical ward for management of her systemic symptoms. The

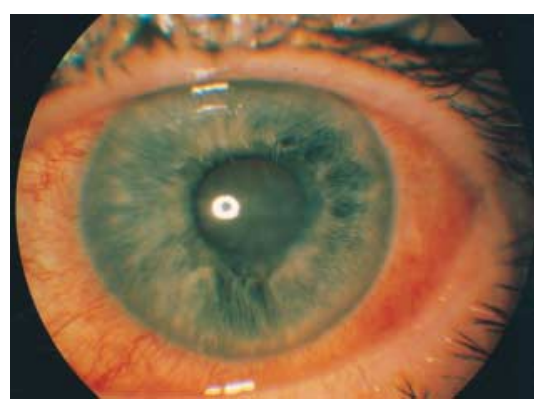

Figure 2 Left eye showing corneal oedema and iris atrophy (more marked in this eye). systemic symptoms improved on antiemetics but she continued to complain of poor vision from both her eyes. Subsequently she was referred to the eye department.

Six months before this referral to the eye clinic, a dilated fundus examination had revealed a macroaneurysm in the right eye not involving the fovea. The visual acuity recorded on that occasion was 6/6 in both eyes.

Ocular examination revealed visual acuities of hand movements in both eyes. The anterior segment photographs of both eyes are shown in figs 1 and 2 . Intraocular pressure was recorded to be $14 \mathrm{~mm} \mathrm{Hg}$ in each eye

\section{QUESTIONS}

(1) Describe the anterior segment photographs.

(2) What is the diagnosis?

(3) How would you manage this patient?

(4) What is the cause?

Postgrad Med J 2003;79:542

\section{Authors' affiliations}

N Dhingra, M T Watts, Department of Ophthalmology, Arrowe Park Hospital, Upton, Wirral, UK

Correspondence to: Mr Dhingra; ndhingra99@yahoo.com Submitted 5 December 2002 Accepted 13 January 2003

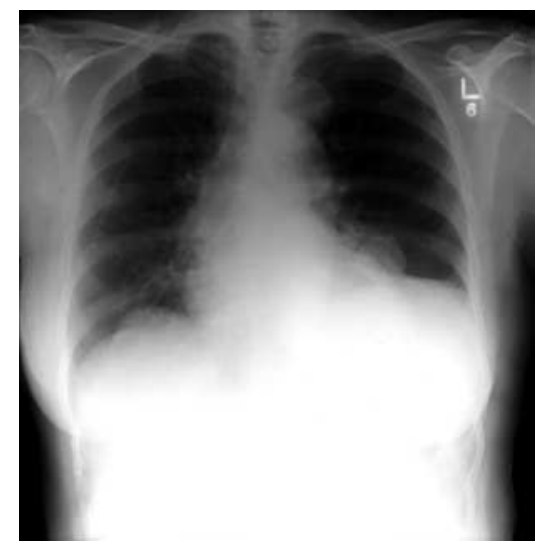

Figure 1 Chest radiograph of patient on admission. space was noted. Abdominal examination was insignificant except for a healed laparotomy scar. Routine blood tests including white cell count, C-reactive protein, and plasma viscosity were unremarkable. Cranial computed tomography showed marked generalised atrophy with evidence of widespread cerebrovascular disease and a small left sided lacunar infarct confirming the clinical diagnosis. There was no evidence of metastatic disease. A chest radiograph (see fig l) performed on admission was reported by the admitting medical officer as multiple cannonball metastases.

\section{QUESTIONS}

(1) What abnormalities are seen on the radiograph?

(2) What is the differential diagnosis? percussion at the left base. A right ination was unremarkable except for decreased breath sounds and dullness to 
(3) What important piece of information from the patient's past medical history is missing and would highlight a possible diagnosis?

(4) What is the most likely diagnosis?

(5) How would you treat this condition?

Postgrad Med J 2003;79:542

\section{Authors' affiliations}

S Buchholz, P Szawarski, S L Dawson, Department of Integrated Medicine, University Hospitals of Leicester NHS Trust, Leicester General Hospital, Gwendolen Road, Leicester LE5 4PW, UK

\section{A rare cause of wheeze in a young adult}

\section{E Moloney, C O'Keane, F Wood, C Burke}

Answers on $p 547$.

A 6 year old Irish girl was referred by her general practitioner to the respiratory outpatient clinic with a nine year history of wheeze on exertion, which was getting progressively worse. She had a minimal response to regular inhaled low dose corticosteroids and required short acting $\beta$-agonists. There was no history of cough, sputum production, or haemoptysis. Her past medical history was unremarkable, and she described her development as normal during her childhood. She was a regular school attender and never smoked. She was on no other medications, and her siblings and other family members were devoid of any breathing difficulties. Physical examination showed a well built young woman in no respiratory distress, with the following physical characteristics: weight, $45 \mathrm{~kg}$; height,

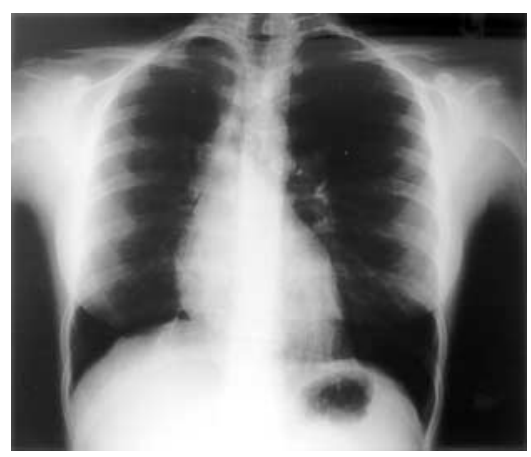

Figure 1 Chest radiograph.
$155 \mathrm{~cm}$; pulse, 80 beats/min; blood pressure, $110 / 60 \mathrm{~mm} \mathrm{Hg}$; and respiratory rate, 18 breaths/min. An examination of the chest revealed forced expiratory rhonchi. The rest of the physical examination was normal. Skin allergy tests showed that she was allergic to the house dust mite and grass mix.

Pulmonary function tests demonstrated a forced expiratory volume in one second $\left(\mathrm{FEV}_{1}\right)$ of $1.84 \mathrm{l} / \mathrm{min}$ (63\% of predicted value), forced vital capacity (FVC) of $2.31 \mathrm{l} / \mathrm{min}$ (75\% of predicted value), and $\mathrm{FEV} / \mathrm{FVC}$ ratio of $80 \%$ of predicted value. Lung volumes, performed by the helium dilution technique, confirmed a restrictive lung defect, with a total lung capacity of 2.83 litres (71\% of predicted value), and a residual volume of 0.45 litres (53\% of predicted value). Plain radiographs and computed tomography of the chest were performed (figs 1 and 2 ). The patient was given a trial of high

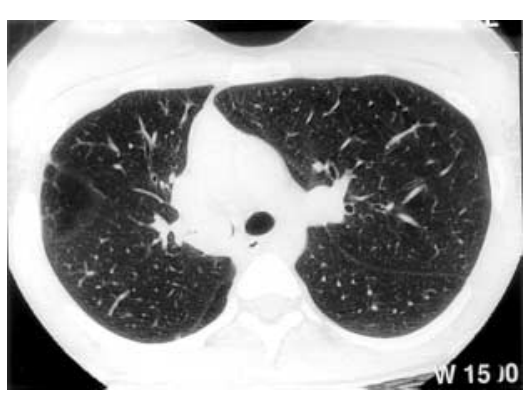

Figure 2 Computed tomography of chest.
Correspondence to: Dr Buchholz; abciximab@doctors.org.uk

Submitted 2 September 2002

Accepted 8 April 2003

dose inhaled corticosteroids, and was also started on inhaled long acting $\beta$-agonists. On review three months later the patient was no better, and bronchoscopy was performed (fig 3).

\section{QUESTIONS}

(1) Describe the findings on radiography and computed tomography.

(2) Describe the findings on bronchoscopy.

(3) What is the most likely diagnosis?

(4) How would you manage this patient? Postgrad Med J 2003;79:543

\section{Authors' affiliations}

E Moloney, C Burke, Department of Respiratory Medicine, James Connolly Memorial Hospital, Dublin, Ireland

C O'Keane, Department of Pathology, Mater

Misericordiae Hospital, Dublin, Ireland

F Wood, Department of Cardio-Thoracic Surgery, Mater Misericordiae Hospital, Dublin, Ireland.

Correspondence to: Dr Moloney; edmoloney@yahoo.com

Submitted 8 January 2003

Accepted 27 January 2003

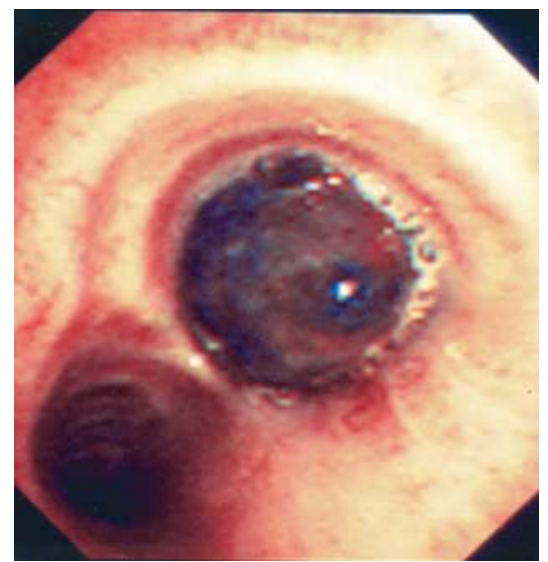

Figure 3 Bronchoscopy at the level of the carina. 
Jaundice

\section{Deep jaundice in an adolescent}

\section{Deutsch, S P Dourakis, V A Sevastianos, A Kaloterakis, S J Hadziyannis}

Answers on $p 548$.

A 16 year old girl, previously healthy, presented with a four day history of $39^{\circ} \mathrm{C}$ fever with chills, loss of appetite, and fatigue. During the past 24 hours, she had dark urine and became progressively jaundiced. She had never smoked or drunk alcohol and took no medications or illicit drugs. Her parents and sibling were in good health.

On examination she was alert but weak, with a presenting fever $39^{\circ} \mathrm{C}$, blood pressure of 100/75 mm Hg, tachycardia (108 beats/min), and tachypnoea (26 breaths/min). The patient was obviously jaundiced and small, painless, tracheal lymph nodes were palpable. The liver was slightly enlarged and the spleen just palpable. There were no signs of chronic liver disease and a split lamp examination for Kayser-Fleischer rings gave negative results. Pregnancy was excluded.

Laboratory testing showed a haemoglobin concentration of $116 \mathrm{~g} / \mathrm{l}$ (mean corpuscular volume $96.3 \mathrm{fl}$ ), leucocytes $13.6 \times 10^{9} / 1$ with $34 \%$ neutrophils $47 \%$ lymphocytes ( $10 \%$ atypical lymphocytes ), $2 \%$ bands, and 5\% monocytes, and platelets $170 \times 10^{9} / 1$. The erythrocyte sedimentation rate was $91 \mathrm{~mm} /$ hour and the C-reactive protein was negative. The bilirubin was $32.4 \mathrm{mg} / \mathrm{dl}(554 \mu \mathrm{mol} / \mathrm{l})$, direct bilirubin $21.8 \mathrm{mg} / \mathrm{dl}(373 \mu \mathrm{mol} / \mathrm{l})$, alanine aminotransferase $305 \mathrm{IU} / \mathrm{l}$, aspartate aminotransferase 178 IU/l, alkaline phosphatase $178 \mathrm{IU} / \mathrm{l}$ (normal value 20-130), $\gamma$-glutamyltransferase $110 \mathrm{IU} / 1$ (normal value 10-75), and lactate dehydrogenase 1225 IU/l. Serum albumin was $38 \mathrm{~g} / \mathrm{l}$ and globulins $39 \mathrm{~g} / \mathrm{l}$. Protein electrophoresis revealed $47.3 \%$ albumins, $2.4 \% \quad \alpha_{1}$-globulins, $11.0 \% \quad \alpha_{2}$ globulins, $12.6 \% \beta$-globulins, and $23.4 \%$ $\gamma$-globulins. The immunoelectrophoresis showed: IgG $13.4 \mathrm{~g} / \mathrm{l}$ (normal value 6.9-16.2) IgA $2.75 \mathrm{~g} / \mathrm{l}(0.68-3.80)$, and IgM $2.94 \mathrm{~g} / \mathrm{l}(0.60-2.63)$. The prothrombin time, partial thromboplastin time, and the fibrinogen level were normal with negative fibrinogen degradation products. Serological tests for HIV, cytomegalovirus, and hepatitis viruses $\mathrm{A}$, $\mathrm{B}$, and $\mathrm{C}$ were negative. The rapid latex agglutination test for heterophil antibodies was negative. Autoantibodies (antinuclear, antimitochondrial, smooth muscle, antiliver-kidney microsomal, p-antineutrophil cytoplasmic) were not detected and the serum complement level was within normal limits. The blood ceruloplasmin and copper levels was normal and the urinary copper was not increased.

Chest radiography and electrocardiography were normal. The abdominal ultrasound showed hepatomegaly, no dilated bile ducts, and the spleen had a span of $12.4 \mathrm{~cm}$.

On the third hospital day, her general condition markedly deteriorated and a rapid fall in haemoglobin to $63 \mathrm{~g} / \mathrm{l}$ with a reticulocyte count of $2.5 \%$ were found. The jaundice deepened, with an elevation in total bilirubin up to $48.1 \mathrm{mg} / \mathrm{dl}$ (833 $\mu \mathrm{mol} / \mathrm{l}$ ) and direct bilirubin 30.8 $\mathrm{mg} / \mathrm{dl}(526 \mu \mathrm{mol} / \mathrm{l})$. The lactate dehydrogenase further increased. The Coombs test was negative.

\section{QUESTIONS}

(1) What is the main differential diagnosis of this patient's initial syndrome?

(2) What is the laboratory test of choice you would perform on the third hospital day?

(3) What is the final diagnosis and the treatment of choice in this case?

Postgrad Med J 2003;79:544

Authors' affiliations

M Deutsch, S P Dourakis, V A Sevastianos,

A Kaloterakis, S J Hadziyannis, B Academic

Department of Internal Medicine, Athens,

Greece

Correspondence to: Dr Deutsch; kostam@ath.forthnet.gr

Submitted 11 November 2002

Accepted 24 January 2003 